\title{
Comparative analysis of human and bovine teeth: radiographic density
}

\author{
Jefferson Luis Oshiro Tanaka ${ }^{(a)}$ \\ Edmundo Medici Filho(b) \\ José Antônio Pereira Salgado(c) \\ Miguel Angel Castillo Salgado(d) \\ Luiz Cesar de Moraes ${ }^{(b)}$ \\ Mari Eli Leonelli de Moraes(e) \\ Julio Cezar de Melo Castilho(f)
}

(a) MSc, Doctoral Graduate Student, School of Dentistry of São José dos Campos, São Paulo State University (UNESP), São José dos Campos, SP, Brazil.

(b) Professor \& Chair; (e)Assistant Professor; (f) Associate Professor - Department of Diagnosis and Oral Surgery, School of Dentistry of São José dos Campos, São Paulo State University (UNESP), São José dos Campos, SP, Brazil.

(c) PhD, Dentist of the Department of Social Dentistry and Children's Clinic, School of Dentistry of São José dos Campos, São Paulo State University (UNESP), São José dos Campos, SP, Brazil.

(d) Assistant Professor, Department of Biosciences and Oral Diagnosis, School of Dentistry of São José dos Campos, São Paulo State University (UNESP), São José dos Campos, SP, Brazil.

\begin{abstract}
Since bovine teeth have been used as substitutes for human teeth in in vitro dental studies, the aim of this study was to compare the radiographic density of bovine teeth with that of human teeth to evaluate their usability for radiographic studies. Thirty bovine and twenty human teeth were cut transversally in 1 millimeter-thick slices. The slices were X-rayed using a digital radiographic system and an intraoral X-ray machine at $65 \mathrm{kVp}$ and $7 \mathrm{~mA}$. The exposure time $(0.08 \mathrm{~s})$ and the targetsensor distance $(40 \mathrm{~cm})$ were standardized for all the radiographs. The radiographic densities of the enamel, coronal dentin and radicular dentin of each slice were obtained separately using the "histogram" tool of Adobe Photoshop 7.0 software. The mean radiographic densities of the enamel, coronal dentin and radicular dentin were calculated by the arithmetic mean of the slices of each tooth. One-way ANOVA demonstrated statistically significant differences for the densities of bovine and human enamel $(p<0.05)$ and for bovine and human coronal dentin $(p<0.05)$. No statistically significant differences were found for the bovine and human radicular dentin $(p>0.05)$. Based on the results, the authors concluded that: a) the radiographic density of bovine enamel is significantly higher than that of human enamel; b) the radiodensity of bovine coronal dentin is statistically lower than the radiodensity of human coronal dentin; bovine radicular dentin is also less radiodense than human radicular dentin, although this difference was not statistically significant; c) bovine teeth should be used with care in radiographic in vitro studies.
\end{abstract}

Descriptors: Tooth; Cattle; Humans; X-Rays; Radiography, dental.

\author{
Corresponding author: \\ Jefferson Luis Oshiro Tanaka \\ Faculdade de Odontologia de São José dos \\ Campos - UNESP \\ Av. Eng ${ }^{\circ}$. Francisco José Longo, 777 \\ Jd. São Dimas \\ CEP: 12245-000 \\ E-mail: jefftanaka@uol.com.br
}

Received for publication on Dec 11, 2006

Accepted for publication on Sep 05, 2007 


\section{Introduction}

Animal teeth have been used in several in vitro studies recently. Bovine teeth are the most common option chosen by most researchers, since they are easily obtained and because the ethics committees are encouraging their use as an alternative for human teeth. ${ }^{1}$

Human dentin is composed of $70 \%$ of inorganic material, $18 \%$ of organic material and $12 \%$ of water. Its structural unit includes peri- and intertubular mineralized matrix, the content of the dentin tubules (the odontoblastic prolongations) and the organic material of the periodontoblastic space. The dentin mass of young teeth has a quite uniform degree of mineralization. However, the enamel-dentin surface, the interglobular dentin and the pulpar dentin are less mineralized. More than $90 \%$ of the organic material of dentin is collagen, distributed in a uniform pattern over the dentin. Nevertheless, the mantle dentin and the pre-dentin seem to contain more organic components than the body of the dentin. The main mass of organic material is uniformly distributed in the intertubular matrix. ${ }^{2}$

Structurally, bovine teeth have a higher number of dentin tubules next to the pulp, as occurs with human teeth. However, human teeth have a smaller number of dentin tubules next to the enamel, whereas the density of tubules next to the enamel in bovine teeth is almost the same as that found on layers next to the pulp. The diameter of the dentin tubules is narrower on the layers next to the enamel and wider on the layers next to the pulp. ${ }^{3,4}$ The distribution of the intertubular dentin is not uniform on the surroundings of the pulp in bovine teeth. ${ }^{3}$

There is also a variation of tubular density per $\mathrm{mm}^{2}$. This variation is also dependant on the type of teeth and on the layer of dentin. ${ }^{4}$ Compared to human dentin, bovine dentin has a higher concentration of dentin tubules per square millimeter, ${ }^{4,5}$ although this difference is small. ${ }^{4}$ The superficial layers of human coronal dentin have less tubules than the deeper layers. On the other hand, bovine teeth have almost the same density of tubules both on the superficial and on the deeper layers of dentin. ${ }^{4}$ On average, the diameter of the dentin tubules of bovine teeth is greater than that of the dentin tubules of human teeth, ${ }^{4,5}$ although the difference is not statistically significant. Moreover, the tubular diameter of the external layers of bovine teeth is smaller than that of the internal layers, ${ }^{4}$ but the percentage of intertubular dentin is the same as in human teeth. ${ }^{5}$ However, Falla-Sotelo et al. ${ }^{6}$ (2005), in a study about the concentration of trace elements of human, bovine and swine teeth, did not observe statistically significant differences in the concentration of $\mathrm{Ca}$ and $\mathrm{P}$ in the enamel and dentin of the three types of teeth.

Comparative in vitro studies have found that microleakage is higher on the margins of the restorations of bovine teeth compared to human teeth. ${ }^{7}$ Bovine teeth have also been employed in studies about endodontic filling materials, ${ }^{8}$ mechanical effects of toothbrushes on the enamel surface, ${ }^{9}$ grinding of diamond burs, ${ }^{10}$ and the effect of a chemical system of caries removal. ${ }^{11}$ Some authors affirmed that bovine teeth can also be used as a substitute for human teeth in adhesion tests of composites and resin-modified cements, ${ }^{12,13}$ as long as these tests are made on enamel or on the superficial surfaces of dentin. ${ }^{12}$

Radiographically, the enamel of human teeth is more radiodense than the cementum and dentin. ${ }^{14}$ However, only a few studies compared the radiographic densities of human and bovine teeth. ${ }^{1} \mathrm{Be}-$ cause of the difference of the microstructures of human and bovine teeth, and because of the differences of the results observed by studies using human or bovine teeth, the aim of the present study was to compare the radiographic density of the enamel and dentin of human teeth and bovine teeth and evaluate their usability in radiographic in vitro studies.

\section{Material and Methods}

Twenty sound human third molars and thirty sound bovine upper incisors were stored in physiological solution to keep their humidity. The human third molars were impacted teeth with indication for surgical extraction. The bovine teeth were obtained from a local slaughterhouse.

The teeth were numbered in a sequence according to their type $(1 \mathrm{H}, 2 \mathrm{H}, \ldots, 20 \mathrm{H}$, for the human 
teeth, and $1 \mathrm{~B}, 2 \mathrm{~B}, \ldots, 30 \mathrm{~B}$ for the bovine teeth) and cut transversally in 1 millimeter-thick slices with an Exetec ${ }^{\circledR}$ Labcut 1010 slicer (Exetec Corp., Enfield, CT, USA). The slices were numbered according to their occlusal-apical or incisal-apical position (C1, C2, C3 for the coronal slices, and R1, R2, R3 for the root slices). Therefore, each slice could be identified by tooth and slice number (i.e.: slice $2 \mathrm{~B}$ $\mathrm{C} 3$ was slice number 3 of the crown of bovine tooth number 2). The number of slices varied according to the size of the teeth. The occlusal/incisal sections of the crowns were excluded from the study since they would contain the oclusal/incisal layer of enamel over dentin, which could interfere in the density results.

All the slices were imaged on a direct digital radiographic sensor (Radiovisiography, Trophy ${ }^{\circledR}$, Toulouse, France) with an intraoral X-ray machine (GENDEX 765DC, Gendex ${ }^{\circledR}$, Lake Zurich, IL, USA), at $65 \mathrm{kVp}, 7 \mathrm{~mA}$, and $0.08 \mathrm{~s}$ of exposure.
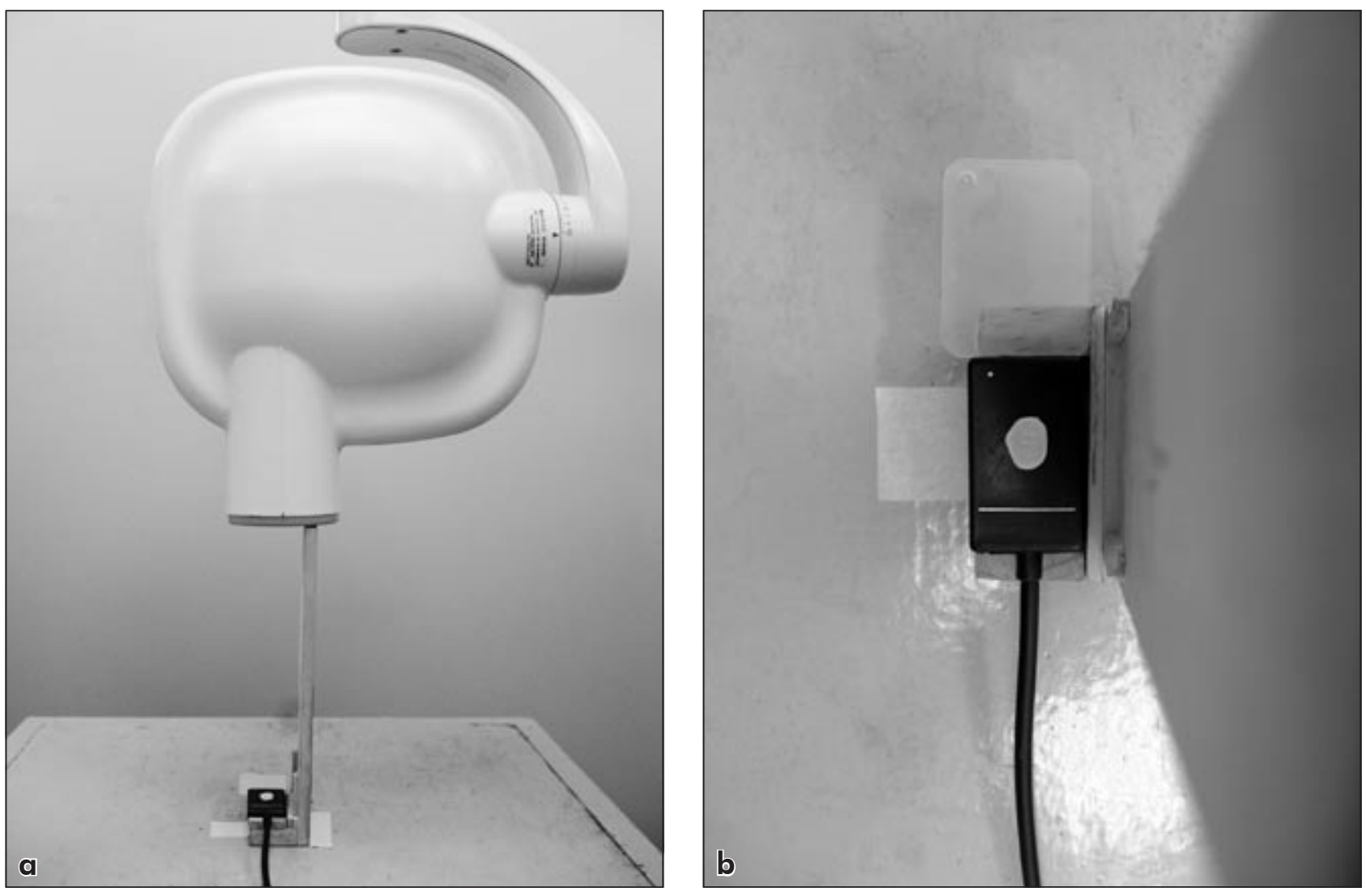

Figure 1 - (a) Sensor placed in the special device; X-ray tube aiming at the sensor; (b) Tooth slice positioned on the center of the sensor. 

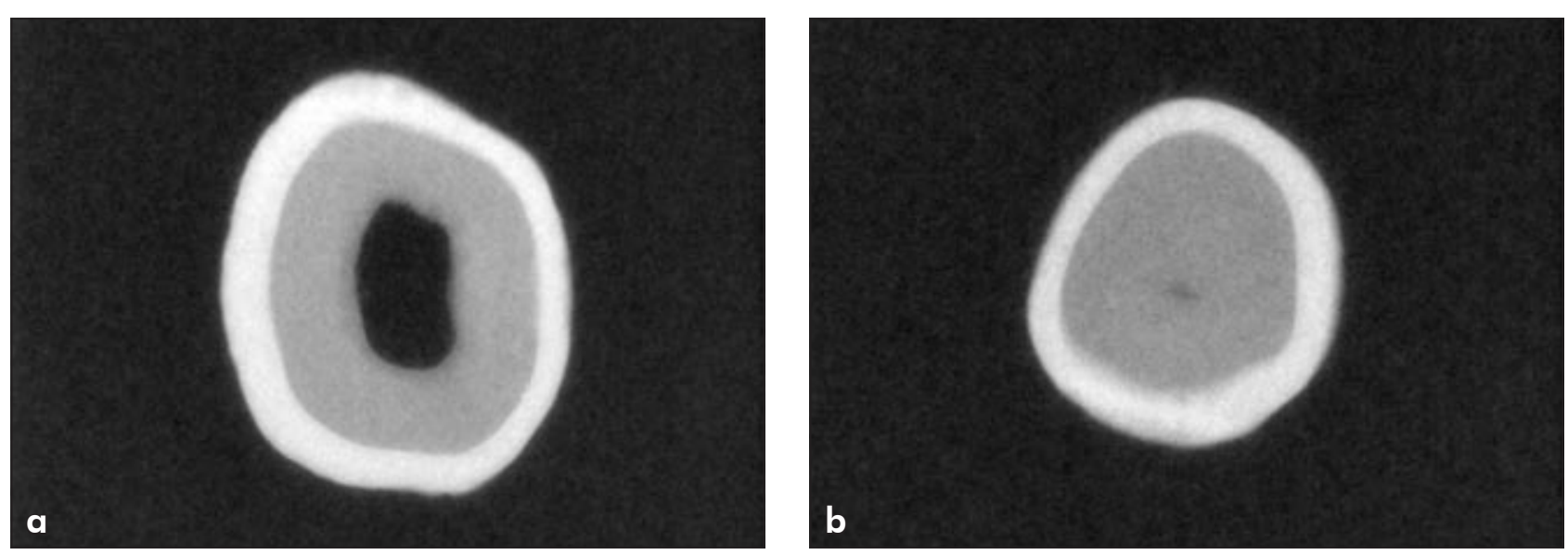

Figure 2 - (a) Radiographic image of a bovine tooth slice; (b) Radiographic image of a human tooth slice.

Table 1 - $n$, mean and standard-deviation (SD) of the optical densities of enamel, coronal dentin and radicular dentin for each group.

\begin{tabular}{c|r|r|c|c|c|c}
\hline & $\begin{array}{c}\text { Bovine } \\
\text { enamel }\end{array}$ & $\begin{array}{c}\text { Human } \\
\text { enamel }\end{array}$ & $\begin{array}{c}\text { Bovine } \\
\text { coronal dentin }\end{array}$ & $\begin{array}{c}\text { Human } \\
\text { coronal dentin }\end{array}$ & $\begin{array}{c}\text { Bovine } \\
\text { root dentin }\end{array}$ & $\begin{array}{c}\text { Human } \\
\text { root dentin }\end{array}$ \\
\hline $\mathrm{N}$ & 30.00 & 20.00 & 30.00 & 20.00 & 30.00 & 20.00 \\
\hline Mean & 224.36 & 221.48 & 171.52 & 174.67 & 216.66 & 217.20 \\
\hline SD & 2.27 & 4.11 & 3.65 & 5.72 & 2.12 & 3.01 \\
\hline Median & 224.90 & 221.30 & 172.52 & 174.25 & 216.78 & 217.79 \\
\hline Minimum & 219.12 & 210.23 & 159.70 & 166.81 & 211.12 & 208.78 \\
\hline Maximum & 228.27 & 226.76 & 176.07 & 190.89 & 219.75 & 221.72 \\
\hline
\end{tabular}

values of the selected structure in each slice according to their grayscale level ( 0 to 255). The density of the enamel, coronal dentin and root dentin of each tooth was calculated by the mean density values of each slice.

ANOVA one-way test was used to compare the mean density values of the enamel, coronal dentin and root dentin of human and bovine teeth to test the hypothesis that there are no statistically significant differences between these mean values.

\section{Results}

Table 1 displays the values of $n$, mean and the standard-deviation of the optical densities of the enamel, coronal dentin and root dentin in each group.

Graph 1 represents the mean values and the standard-deviation of the optical densities of enamel, coronal dentin and root dentin for each group.

Table 2 displays the $p$-values of the comparisons of the mean values of enamel, coronal dentin and root dentin of bovine and human teeth's optical densities.

\section{Discussion}

Because of the increasing difficulty in obtaining human teeth for dental research, and because of the requirements made by ethics committees about their use, many researchers have preferred to use animal teeth. Bovine teeth have been suggested as possible substitutes for human teeth because they can be easily obtained, since bovines are widely slaughtered for human consumption and their teeth have no commercial purposes. ${ }^{1,10,15}$ However, the chemical, structural, anatomical and radiographic characteristics of those teeth are not necessarily similar to those of human teeth. Therefore, the results of studies that use bovine teeth may be jeopardized as a consequence of these differences. Thus, the characteristics of the hard tissues of animal teeth are the 


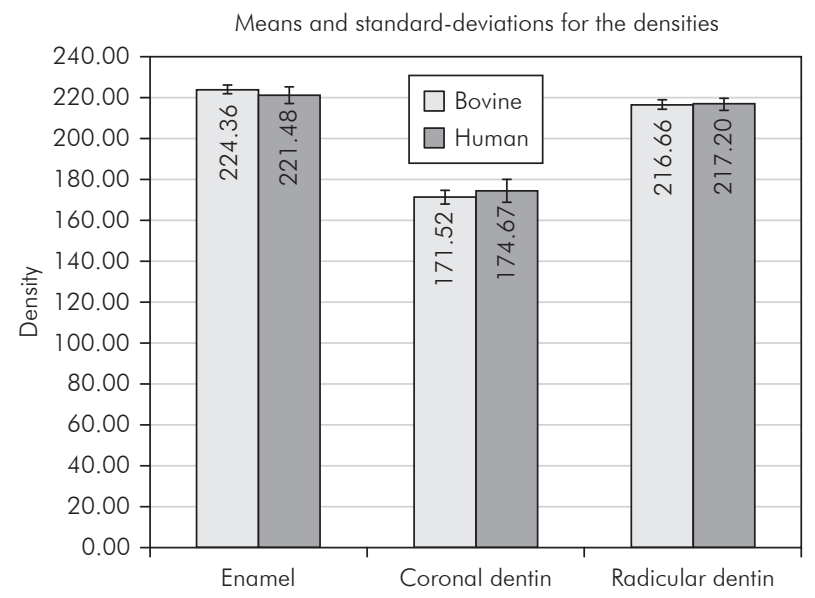

Graph 1 - Mean and standard-deviation (SD) values of the optical density of enamel, coronal dentin and root dentin for each group.

Table 2 - $p$-values of the comparisons of the mean values of enamel, coronal dentin and root dentin of bovine and human teeth.

\begin{tabular}{c|c|c|c}
\hline & $\begin{array}{c}\text { Bovine enamel } \\
\times \text { Human } \\
\text { enamel }\end{array}$ & $\begin{array}{c}\text { Bovine coronal } \\
\text { dentin } \times \text { Human } \\
\text { coronal dentin }\end{array}$ & $\begin{array}{c}\text { Bovine root dentin } \\
\times \text { Human root } \\
\text { dentin }\end{array}$ \\
\hline$p$-value & 0.003 & 0.021 & 0.455 \\
\hline
\end{tabular}

$\alpha(0.05)$.

main variable to be taken into account when choosing possible animal substitutes for human teeth. ${ }^{1}$

Since there are structural differences between human and bovine teeth, disparities in the human and bovine teeth's radiographic densities are also expected. Such differences may be due to dissimilarities of constitution and mineral quantity of each type of teeth. We have observed in the present study that, on average, the density of bovine enamel was higher than the density of human enamel. The statistics demonstrated that this difference was statistically significant $(\mathrm{p}<0.05)$. Fonseca et al. ${ }^{1}$ (2004), in a similar study, concluded that the radiodensity of human and bovine enamel was similar. The higher density of the bovine enamel found in our study is an indication that these teeth are more mineralized than human teeth or that mineral composition of bovine enamel is slightly different from that of human teeth. Such disparities may be due to differences of alimentary habits or even because of the type of management and age of the herd from which the teeth were acquired. ${ }^{16}$ A strong evidence of such possible mineral composition disparities is the observed inequality of action of a chemical system for caries removal in human and bovine teeth. ${ }^{11}$ However, Pinelli et al. ${ }^{10}$ (2004), in a study about the wear of diamond burs on human and bovine enamel, observed that more time is required for the wearing out of those burs on human dental tissue. Imfeld ${ }^{9}$ (2001) detected no differences in the mechanical action of a certain type of toothbrush on human and bovine teeth. On the other hand, bovine teeth seem to present higher levels of microleakage on the margins of cervical restorations made with glass ionomer and resin composites. ${ }^{7}$ Studies also demonstrated that there are differences in the marginal microleakage of many adhesive systems used for human and bovine teeth. ${ }^{15}$ This suggests the existence of disparities in the chemical composition of bovine teeth compared to that of human teeth. Since adhesive systems are developed according to the characteristics of human teeth, a reduced efficacy of these materials on substrates other than human is likely to be observed. Moreover, according to the results of the present study, probably there are differences of composition between human and bovine teeth, since a statistically significant difference between the bovine and human enamel was observed.

On the other hand, we observed that the radiodensity of bovine coronal dentin was, on average, lower than that of the human coronal dentin. This difference was also statistically significant. Fonseca et al. ${ }^{1}$ (2004) also observed that bovine dentin is less dense than human dentin, but their results demonstrated that these differences are small. It is known that there are differences of arrangement, density and diameter between human and bovine dentin. The density of human dentin tubules is smaller next to the enamel and their diameter is smaller compared to bovine's, ${ }^{5}$ although both types of teeth have narrower tubular diameters on the layers next to the enamel and wider diameters next to the pulp. ${ }^{3}$ Reis et al. ${ }^{13}$ (2004) found similarities in the structure of human and bovine teeth using Scanning Electron Microscope (SEM) observation. How- 
ever, studies have observed a lower performance of adhesive systems in the deeper layers of bovine teeth. ${ }^{12}$ This indicates the existence of dissimilarities in the disposition and quantity of dentin tubules, in chemical composition of dentin or an association of these factors. ${ }^{12}$

Studies about the ideal level of radiopacity of composites have indicated that the materials should have a radiopacity similar to that of enamel so that it would not mask or hinder the detection of recurrent caries. ${ }^{17,18}$ However, these studies were made on human teeth. Thus, special care should be taken when using bovine teeth for similar studies to avoid errors in the interpretation of the results, since bovine enamel is more radiodense than human enamel,

\section{References}

1. Fonseca RB, Haiter-Neto F, Fernandes-Neto AJ, Barbosa GAS, Soares CJ. Radiodensity of enamel and dentin of human, bovine and swine teeth. Arch Oral Biol. 2004;49(11):919-22.

2. Mjör IA. Human coronal dentin: structure and reactions. Oral Surg Oral Med Oral Pathol. 1972;33(5):810-23.

3. Bonfim MDC, Anauate Netto C, Youssef MN, Kuchinski FB. Estudo micromorfológico comparativo das dentinas: humana e bovina. Pesqui Odontol Bras. 2000;14(suplemento):32 [resumo I167].

4. Schilke R, Lisson JA, Bauss O, Geurtsen W. Comparison of the number and diameter of dentinal tubules in human and bovine dentine by scanning electron microscopic investigation. Arch Oral Biol. 2000;45(5):355-61.

5. Miranda MS, Lamosa AC, Dias K, Teixeira FB, Lopes MF. Comparação em MEV entre a dentina humana e a bovina. Pesqui Odontol Bras. 2001;15(suplemento):80 [resumo A081].

6. Falla-Sotelo FO, Rizzuto MA, Tabacnicks MH, Added N, Barbosa MDL. Analysis and discussion of trace elements in teeth of different animal species. Br J Physics. 2005;35(3B):761-2.

7. Abuabara A, Santos AJS, Aguiar FHB, Gomes FM, Lovadino JR. Avaliação quantitativa da infiltração marginal com esmalte humano, bovino e suíno. Pesqui Odontol Bras. 2002;16(suplemento):55 [resumo Ia181].

8. Vizgirda PJ, Liewehr FR, Patton WR, McPherson JC, Buxton TB. A comparison of laterally condensed gutta-percha, thermoplasticized gutta-percha, and mineral trioxide aggregate as root canal filing materials. J Endod. 2004;30(2):103-6.

9. Imfeld T. Comparison of the mechanical effects of a toothbrush and standard abrasive on human and bovine dentin in vitro. J Clin Dent. 2001;12(4):92-6. and bovine coronal dentin is less radiodense than human coronal dentin.

\section{Conclusions}

Based on the results of the present study, we concluded that:

a. The radiodensity of bovine enamel is significantly higher than the radiodensity of human enamel.

b. The radiodensity of bovine coronal dentin is statistically lower than the radiodensity of human coronal dentin, and bovine radicular dentin is also less radiodense than human radicular dentin, but this difference is not statistically significant.

c. Bovine teeth should be used with care in radiographic in vitro studies.

10. Pinelli LAP, Faria IR, Marcelo CC, Pita APG, Silva RHBT, Guaglianoni DG. Estudo fotomicrográfico do desgaste de pontas diamantadas em diferentes substratos. Cienc Odontol Bras. 2004;7(4):60-6.

11. Puppin-Rontani RM, Caldo-Teixeira AS. Effect of sodium hypochlorite on different substrates - A SEM analysis. Acta Microscopica. 2003;12(1):169-73.

12. Nakamichi I, Iwaku M, Fusayama T. Bovine teeth as possible substitutes in the adhesion test. J Dent Res. 1983;62(10):107681.

13. Reis AF, Giannini M, Kavaguchi A, Soares CJ, Line SR. Comparison of microtensile bond strength to enamel and dentin of human, bovine, and porcine teeth. J Adhes Dent. 2004;6(2):117-21.

14. Curtis PM, Von Fraunhofer JA, Farman AG. The radiographic density of composite resins. Oral Surg Oral Med Oral Pathol. 1990;70(2):226-30.

15. Resende AM, Gonçalves SEP. Evaluation of the marginal leakage in human and bovine teeth with two different adhesive systems. Cienc Odontol Bras. 2002;5(3):38-45.

16. Olhoff RD, Pereira IRA, Luz NC, Machado FG. Incidência de alterações dentárias em um rebanho bovino leiteiro. Archiv Vet Scienc. 2005;10(2):95-100.

17. Espelid I, Tveit AB, Erickson RL, Keck SC, Glasspoole EA. Radiopacity of restorations and detection of secondary caries. Dent Mater. 1991;7(2):114-7.

18. Goshima T, Goshima Y. The optimum level of radiopacity in posterior composite resins. Dentomaxillofac Radiol. 1989;18(1):19-21. 